\title{
Quality Content in Distance Education
}

\author{
Ezgi Pelin Yildiz , Aytekin İşman \\ Institute of Educational Sciences, Sakarya University, Sakarya, Turkey
}

Copyright $(2016$ by authors, all rights reserved. Authors agree that this article remains permanently open access under the terms of the Creative Commons Attribution License 4.0 International License

\begin{abstract}
In parallel with technological advances in today's world of education activities can be conducted without the constraints of time and space. One of the most important of these activities is distance education. The success of the distance education is possible with content quality. The proliferation of e-learning environment has brought a need for content production. In educational process one of the most important subjects is learning contest. Learning contest represents an entire course, subject materials, content modules, learning objects about courses, information resources and periodicals. Quality of the content in distance education systems come before the factors that determine the quality of education.
\end{abstract}

Keywords Distance Education, E-learning, Quality, Content

\section{Introduction}

Many new concepts have emerged within education using information and communication technology. One of these is the concept of distance education. Distant education is an institutive education activity which brings; teaching materials with communication tecnologies, teachers and students in different places together. Distance learning is one of the rapidly developing fields of education (Boas et al. [1]). In other words distance education expresses the model of an education system that the student and teachers in different places make the learning-teaching activities with communication technologies and mail services real (İşman, [2]). Distance learning is an important tool that meets the learning needs of young people and adults. Distance learning has a great potential at various levels.

The development of modern information technology has encouraged the advance of distance higher education (Zhao \& Li, [3]). Quality assurance systems that improve the quality of distance higher education haves been established. In this context, distance education and the accreditation of quality assurance systems are created. Accreditation in education is a way of verification of a definite institution's education quality which has been approved by academic quality approval and presented to a person, group or people who needs education. Accreditation is a concept developed in education to agree on certain standards. One of the most important institutions providing the accreditation of distance education institutions is the Distance Education and Training Council (DETC). According to the organization's 1998 data the average age of Internet-based distance education students participating in the programme was 31 and the most important problem in the frequently asked questions section is the validity level of the diplomas or certificates in the other countries that they take this education in another institutions. While the studies of accreditation are still going on these kinds of questions subsist in the part of problems at education institutions. Accredited institutions have provided standardised, Internet-based distance education programmes that are implemented by educational institutions which haves provided a way to solve these problems (Gürol \& Sevindik, [4]).

It has been observed that there has been an increase in the number of universities across the world implementing distance education through innovative forms of education. Information on distance learning is transferred to the students by communication Technology and in this point the quality control system of distance education is featuring. (Batura et al. [5]). A quality control system is expected to be fulfilled in a repeated 4-step cycle; planning, monitoring, organizing and setting up set up all elements of the system.

Active, social-oriented, creative and self-sufficient educational qualifications are the main criteria in the quality of distance education. The supportive factors could be organized as motivation in education, self-organization information and communication technologies with practical experience availability, distance education's psychological and technological adaptation. Quality in distance education can be characterized by three elements: staffing, training and methodological materials, material and technical infrastructure (Batura et al. [5]). Also distance learning is evaluated through quality control conditions, process quality and quality of results. Quality conditions include the training and supply system, the material and technical infrastructure and personnel, process quality includes; education, science and research and management, the quality of the results; two dimensions are discussed: the quality of the students, and an 
external evaluation of graduates is examined by; the employment rate and, unemployment rate. The quality of the students; knowledge, skills and experience are examined. The graduate of external evaluation; the employment rate, unemployment rate and problems are examined. The University of Texas Pan American quality in distance education is discussed from three angles; quality of content, presentation quality and the quality of student services (Davies et al. [6]). The quality of distance education could be evaluated by approaching the learning experiences' results on these identified factors. Especially for the quality content, content experts, instructional designers, media experts, graphic designers and there is a need to be synchronised and work as a team in one or more subject technology officer.

For effective learning in distance education components such as interaction via, text, sound, simple graphical presentations, video presentations, animations, simulations, test systems, should be supported by feedback. The proliferation of e-learning environments has brought the need for the content to be produced together and is one of the most important points to be considered in the educational process of learning content. The quality of content is one of the factors that determine the quality of education in distance learning. Numerous content development tools for distance learning are available. The use of these tools are practical quick to prepare and can bring about very different content. The most important objective in the design of educational content; is that it is easy for users to understand, easy to learn and is an interactive structure. Related features that affect the quality of content include: it should; be interactive with, audio, images, animation, multimedia support, simulation and animation of courses and learning activities to give the work contains questions and tests. The other issue in content quality is to provide the content standards (Balaban, [7]). Therefore it is important to investigate the selection of the Learning Management System (LMS) and Content Management Systems (CMS) soft wares' whether they use the standards or not. Learning Management System software enables the monitoring of user information. It allows the selection and registration of students in distance or blended learning courses the presentation of content, and its assessment and evaluation. Learning Management Systems "LMS" (Learning Management System, LMS) is software that allows the management of learning activities. It allows students and teachers to keep system records and retention reports. It provides learning materials and the ability to share learning materials and discussions, manage course catalogues, receive assignments, enter exams, undertake assignments and provide feedback on the exam (Özaslan, [8]). An instructional management system must have certain characteristics in order to provide full service to its users. The main features it should have are interoperability, primarily with other systems, compliance archiving and file management capabilities, reusability, regulation consistent with learning objectives and supporting other tools used to create quick accessibility of content Word, PowerPoint, Flash, PDF etc. (Altıparmak et al. [9]).
The content management systems are the systems that the web site owner and the other authorised users' private account information (user name, password, ...) with the reached Web site Management panel by using the content that can be changed and add the new ones on the website (text, pictures, music, files, etc.). Web-based programs which means the programs that works on the internet can be run easily to use without the need to install to the private computer and it can be reached from any computer anywhere in the world. The software's that featured in content production are: Adobe Captivate, Adobe Presenter, Adobe Flash Adobe $\mathrm{X}$ pro Raptivity, Camtasia, Articulate, Articulate Engage, Articulate Presenter, Authoware, Lectora, Elicitus, Rapid Intake, Toolbook, Keynote, Webex presentation studio, Articulate studio.

Apart from the need for any software installation without providing rapid content development services that can be used if necessary to give a few examples of websites:

- E-Learning Brothers: It is possible to get the SWF with a flash output by changing the desired content on ready-made templates (www.elearningbrothers.com).

- Panopto: Fast offline content that can be prepared and published (www.panopta.com).

- Presentations 2Go: The program can translate a described course as an accessible content which can be accessed from web save it with the person's shared information of the presentation and image in a conference. (http://www.presentations2go.eu).

Open sources and coded softwares show themselves at development of the contents of distance learning. Open source code is an application development method that presents an easy access to the product's source. It provides a significant advantage in terms of cost open source content and development tools allow people with no professional skills to easily create interactive course content. Almost all software development tools have a graphical user interface. Most of this software also has Turkish language support. All these features provide to prepare a content in a fast and easy way to the content development teams who give a distance education in institutions, instructors and the other people who are responsible for the content development. Open source tools that can be used for content development in distance education are an alternative to commercial software. Today, there are many different functions that offer open source content development In our era there isn't a solution that is "capable of responding to all needs" with the open source code learning management system which is pretty much in number. The learning management systems that will be selected for suiting the aim should to be investigated, compared with each other and should be in a position that answers the institution's needs in the best way by its general outlines. Prominent and general characteristic:

\section{Moodle}

In the world of e-learning platforms Moodle is the most 
widely used open source learning management system software. Each month, the average number of new registrations is 2000 , and it is available to users in 219 countries. Moodle software has spread in Turkey and provides support for the use of the Turkish language. Particularly Moodle as the opening of the Learning management system is a low cost solution to start in the web based online graduate level courses (LMS). Although it is free, open source software will entail costs associated the university and software support. Compared with the cost of commercial software it is preferable due to its lower cost.

Moodle is an open source and open to development learning management system designed to help educators create online courses. The software works under the MySQL and PostgreSQL database systems and in any environment that supports PHP (Linux, Windows, etc.). The model can perform many of the activities that may be required in distance education sites. The most important feature is that teachers and students can use it easily (Altıparmak et al. [9]).

\subsection{Blackboard}

In 1997 Blackboard, an E-learning software of the leading position at areas of its applications and services globally was founded with the aim to increase the innovations in the field of education to reach everywhere and also to spread the productivity with the dissemination. Blackboard's worldwide users portfolio formed of, primary and secondary schools, higher education institutions, public and commercial institutions. Blackboard and it's users seen as the world pioneers in the field of e-learning and Blackboard's online learning application draws the attention as the most commonly used in United States and the most successfully adapted system. Blackboard aims to promote educational innovations everywhere by combining technology with humans; it has accepted this as its mission. Blackboard software has been introduced in two packages: 'Academic Suite' (academic pack) and 'Commerce Suite' (commercial package). The commonly used 'Blackboard Academic Suite' consists of three separate modules:

\section{Blackboard Learning System}

This provides content preparation and management training.

\section{Blackboard Community System}

This allows the setting up of vibrant online communities, educational institutions and improves the flow of data.

\section{Blackboard Content System}

This is used to store, share and organize the digital content. An electronic portfolio can be prepared to assess student progress.

\section{Sakai}

"Sakai Foundation" is a collaborative and a learning environment (CLE) that reformed under the organisational structure academic, commercial and individual participation which was created under the leadership of Sakai Indiana University, Stanford University, University of Michigan and the University of Valencia Polytechnic. Web-based platform is an independent application that appeals free for over 160 educational institutions' that a lot of users use with the features that support education and open source code. The application of Sakai course management systems besides the many common features they have, including information/document distribution, transferring assignment, online assessment and evaluation, notepad and also live chat modules. Sakai that presents collaborative work environment tools is also suitable for the use of researchers and project groups. Developing the applications under the Sakai Foundation's structure is made by educational institutions and universities individual, based on membership without any profit motive. This community is also working on the identification on open standards for the education and research communities, software solutions and about its integration.

When Moodle and Sakai is compared, it is seen that although Moodle is used more widely in our Country and globally, future aimed investments and supports to Sakai show it will get more shares in the market. Mellon's investment of 2.2 million USD and Hewlett's investment partners' 4.6 million USD fund supports demonstrates Sakai's future brighter.

\section{Atutor}

Atutor is an open source web-based learning content management system (LCMS). A Tutor a software that contains the desired features for the disabled people which determined by The American Society for Training and Development (ASTD). Platform works independently on the server environments which is Microsoft, Linux, UNIX, or Mac. University of Toronto is conducting studies about the creation of standards and continues to develop many projects in this area with Atutor in the first place. Atutor is used by many universities, institutions, research centers and educational institutions.

\section{Dokeos}

Dokeos is a learning management system that based on the open source business model which reformed besides many international institution and organisations with the universities first. It is used in e-learning and blended learning programs by many companies except for academic purposes. Based on the MySQL database and a web-based application is written in PHP. Dokeos is a tool based on web-based e-learning, course management and a collaboration system. Dokeos can perform course management which is about distribution issues, scheduling, progress tracking, text / voice and video with chat, test management and record in. At this moment Dokeos which includes 31 languages is using by many organisations. The main advantage of Dokeos its ease of use and it is a flexible system. With a simple operation it aims to become the main tool for good teaching. In this way users will be presented with the opportunity to devote more in learning by making less effort with Dokeos. 


\section{Efront}

EFront is a content and learning management system for e-learning and human resources management with its easy usage, visual characteristics and SCORM compliance, which include suitable systems to be used for open source coded companies and education institutions. Platform works on MySQL as a database, software architecture as PHP. Besides Efront's enriched version about human resources management, different language supports, LDAP's authentication option and pedagogical content presentations with open source code of educational package is also located. Apart from this, Dimdim's open source code applications have the possibility to form an online certificate for virtual classroom and courses which will be presented a virtual meeting and synchronous education.

\section{Docebo}

Docebo is a content and learning management system which is similar to Efront that keeps open source code companies with the systems which is proper to the use of educational institutions for SCORM compatibility with e-learning and human resources' management and development. Docebo is working as PHP and database on MySQL. In Docebo there is a possibility as e-bulletin for collective informing as well as video conferencing, virtual conversation and meeting.

\section{Estudy}

Estudy, is an open source learning management system that gives special support, especially in computer Science, in addition to the simulation of an ordinary university course management system.

\section{Claroline}

Claroline has been developed on the basis of pedagogical principles. Classroom's traditional structure has been started to move to the collaborative web applications based on the foundation of education.

\section{Drupal}

Open source code content management system of Drupal is a flexible platform that developed by the aim to form many wide features and services with socially interactive learning environments besides the customizable, authorizable content and user management and search capabilities. Web-based platform could be configured on MySQL or PostgreSQL database, in PHP language. Many educational institutions and universities choose Drupal as a content management system.

\section{DotLRN}

Dotlrn is an open source code learning management system that keeps the office supplies that students used about assignments and projects within itself. Dotlrn consists of course management, learning management, content management, and online community management structure. Dotlrn works supportive on the Unix / Linux based servers with AOLServer web application server. The database is PostgreSQL and is compatible with Oracle.

\section{Olat}

Olat, which is used in Switzerland and the University of Zurich, was developed as an open source learning management system. The java based application requires a java-enabled server. MySQL, Postgres and HSQL have been tested and can be used by anyone. The course system's installation and structure is easy. It provides file sharing, chat, discussion forums and support groups. There is strong membership as an intra-Group membership status is available. Olat contains course system scoring mechanism inside itself. It supports online testing and scoring while the user page carries a portal feature. There are survey-based reporting and query features.

\section{Distance Education Uses Areas}

Distance learning is used in almost every area. The method is particularly indispensable especially for school age and background who want to develop themselves or people working in education. In Turkey undergraduate, graduate, including almost all universities in postgraduate education has been implemented.

\section{Advantages and Disadvantages of Distance Learning}

Like any kind of educational program, distance learning comes with a host of pros and cons. Before you enroll in any kind of distance learning program, make sure to carefully consider these in order to be sure you'll be getting an education that meets your personal needs, strengths and career goals.

Distance Learning Advantages

- Lots of flexibility. With distance learning courses, students can complete their course work from just about anywhere, provided there's a computer and internet connection. This allows students to work when and where it is more convenient for them without having to squeeze in scheduled classes to an already busy life.

- No commuting. Taking a course online can be one way to cut down on costly gas or public transportation. Since students can often work from home to complete their class assignments, both time and money are saved in cutting out the trips to and from class.

- Numerous choices for schools. Even if you live in a community with few or no colleges distance learning allows you to choose from a wide variety of schools to complete your education. You may find online schools that specialize in your particular field or one that can provide a great general education. Either way, your options for education will be greatly expanded.

- Lowered costs. Prices for online courses are generally cheaper than their on-campus counterparts and you won't have to worry about commuting, moving or getting meal plans on campus, some additional benefits to learning from home. 
- Learn while working. As distance learning can usually be completed on your own schedule, it is much easier to complete distance learning courses while working than more traditional educational programs. Keeping your job gives you more income, experience and stability while completing your degree giving you less to worry about and more time to focus on your studies.

\section{Distance Learning Disadvantages}

- Lack of social interaction. If the classroom environment is what you love most about learning you may want to take a step back and reconsider distance learning. You'll likely get some interaction on chat rooms, discussion boards and through email, but the experience will be quite different than traditional courses.

- Format isn't ideal for all learners. Not everyone is an ideal candidate for online learning. If you know you have problems with motivation, procrastination and needs lots of individual attention from an instructor you may want to think long and hard before enrolling in an online learning program.

- $\quad$ Some employers don't accept online degrees. While a majority of employers will, there are some who still see a stigma attached to distance learning. Realize that your online degree may not be the ideal tool for some job fields or for future learning.

- Requires adaptability to new technologies. If you've never been one to love working with technology you will probably get a lot less out of an online course than your more tech-savvy counterparts. Make sure you feel comfortable working with computers and with online programs before you sign up for a class.

- Not all courses required to complete the degree may be offered online. It makes sense that more practical majors like nursing aren't offered entirely online, after all, part of the degree is learning to work directly with patients. Find out all the requirements of your degree to see what may need to be completed offline.

\section{Effectiveness of Distance Education among Different Learning Models}

- Universities servicing multiple sites can seek to utilise online education as a cost efficient means to develop skills and education training to numerous sites at once and so reduce time and drive down fixed costs (Childs et al., 2005; Scarafiotti, 2004).

- As the up-scaling of learner groups takes place, then online education can deliver content to numbers beyond the limitations of the bricks and mortar classroom environment. Again, clear efficiencies can be theoretically achieved (Childs et al., 2005; Scarafiotti, 2004; Lee, Yoon, \& Lee, 2009) as excess or overflow demand is catered for which might previously have gone elsewhere.

- From the learner point of view, online education is about convenience and the flexibility of study.
Translated into the commercial sector, this allows the delivery of 'just-in-time' training as and when necessary, and in the education sector it can mean wider access for non-traditional students (i.e. adult returners) (Childs et al., 2005; Winterbottom, 2007; Meyer, 2003; Wang \& Woo, 2007).

- Online education systems have the capacity to track user progress and also to assess their competencies through interactive content and related quizzes and assessments in a much more instantaneous manner than the large lecture hall environment. (Childs et al., 2005).

- There are clear cost savings to student commuters being able to work from home and progress their studies; likewise in the commercial sector where online education can save many thousands of pounds annually on reduced transport costs for classroom-based training events (Childs et al., 2005).

\section{Result}

The concept of distance education is of great importance in developing information and communication technologies. Today, in primary schools to universities the concept of distance education is used in many areas, sometimes as an alternative to, and sometimes independently from, formal education.

Within the concept of distance education content development is of great importance. The prepared content is one of the main components that determine the quality of education. The most important objectives in the design of educational content is that it is; easy for users to understand, easy to learn, and has an interactive structure. Related features that affect the quality of content are; it should be interactive with audio, images, animation and so on. In addition, it should have multimedia support, simulation and the animation of courses and learning activities, to include the work that contains questions and tests. Another issue with content standards is to ensure the quality of the content. Therefore, it is important to research at this point whether the chosen Learning Management System (LMS) and Content Management System (CMS) softwares' use the standards or not. According to the purpose of the chosen learning management system and content management systems' should answer with their best for the needs of the organisation which will use the application and be examined with their general characteristics, be compared with each other.

\section{REFERENCES}

[1] Boas, A., Andrade, G., Hamtini, T. \& Sousa, S. [2011]. Tutors and University Teachers' Perception about Quality Assurance in Distance Education. IEEE Global Engineering Education Conference (EDUCON). 
[2] Isman, A. [2011]. Distance Education. Chapter [1]. Pegem Academy Publishing. [1].

[3] Zhao, J. \& Li, X. [2009]. Inspiration from an Analysis of the British and American Quality Assurance System of Distance Higher Education. First International Workshop on Education Technology and Computer Science.

[4] Gürol, M. \& Sevindik, T. [2004]. Technological Aspect of Distance Education. XIII. National Educational Sciences Congress, Inonu University, Faculty of Education, Malatya.

[5] Batura, M. Krasovski, V. \& Tavgen, I. [2008]. Quality Assuring of Distance Education. Belarusian State University of Informatics and Radioelectronics, Minsk, Belarus.

[6] Childs, S., Blenkinso, E., Hall, A., \& Walton, G. (2005). Effective e-learning for health professionals and students barriers and their solutions. A systematic review of the literature - findings from the hexl project. Health information and libraries journal, 22(0), 20-32.

[7] Davies, G., Cover, C., Fowler, W. \& Guzdial, M. [2001]. Quality In Distance Education. ASEE/IEEE Frontiers In Education Conference.

[8] Balaban, M. [2012]. Distance Education in the world and Turkey and a Project Proposal. Isik University, Istanbul.

[9] Ozaslan, Y. [2008].Distance Education Practice for Open Source Code Learning Management Systems. inet-tr'08 XIII. Internet Conferance Notifications in Turkey 22-23 December 2008. Orta Doğu Teknik University, Ankara.

[10] Lee, B., Yoon, J.,\& Lee, I. (2009). Learners' acceptance of e-learning in South Korea: Theories and results. Computers \& Education, 53(4), 1320-1329.

[11] Altıparmak, M., Kurt, I. \& Kapıder, M. [2011]. E-Learning and Open Source Learning Management Systems in Distance Education. Academic Information'11 - XIII. Academic Computing Conference Proceedings, Inonu University, Malatya.

[12] Scarafiotti, C. (2004). Five important lessons about the cost of e-learning. New directions for community colleges, (128), $39-46$.
[13] Winterbottom, S. (2007). Virtual lecturing: Delivering lectures using screencasting and podcasting technology. Planet, 18, 6-8.

[14] Meyer, K. A. (2003). Face-to-face versus threaded discussions: The role of time and higher-order thinking. Journal of asynchronous learning networks, 7(3), 55-65.

[15] Advantages and Disadvantages of Distance Learning Retrieved from: http://www.iadl.org.uk/Article20.htm Date: 18.10.2016

[16] Wang, Q., \& Woo, H. L. (2007). Comparing asynchronous online discussions and face-to-face discussions in a classroom setting. British journal of educational technology, 38(2), 272-286.

[17] For more information about Open Source Code Learning Management Systems;

[18] ATutor: http://www.atutor.ca/

[19] Sakai: http://www.sakaiproject.org/

[20] Dokeos: http://www.dokeos.com/

[21] Drupal: http://drupal.org/

[22] eFront: https://www.efrontlearning.com/

[23] Blackboard: http://blackboard.org/

[24] DotLRN: http://www.dotlrn.org/

[25] Docebo: http://www.docebo.org/

[26] Moodle: http://moodle.org/

[27] OLAT: http://www.olat.org/

[28] Estudy: http://estudy.sourceforge.net/

[29] Claroline: http://www.claroline.net/

[30] E-Learning Brothers: www.elearningbrothers.com

[31] Presentations 2Go: http://www.presentations2go.eu

[32] Panopto: www.panopta.com4 